\title{
Population-based strategies for Helicobacter pylori-associated disease management: a Japanese perspective
}

\author{
Seiji Shiota, \\ Department of Environmental and Preventive Medicine, Oita University Faculty of Medicine, 1-1 \\ Idaigaoka, Hasama-machi, Yufu-City, Oita 879-5593, Japan and Department of General Medicine, \\ Oita University Faculty of Medicine, 1-1 Idaigaoka, Hasama-machi, Yufu-City, Oita 879-5593, Japan \\ Kazunari Murakami, \\ Department of General Medicine, Oita University Faculty of Medicine, 1-1 Idaigaoka, Hasama- \\ machi, Yufu-City, Oita 879-5593, Japan \\ Toshio Fujioka, and \\ Department of General Medicine, Oita University Faculty of Medicine, 1-1 Idaigaoka, Hasama- \\ machi, Yufu-City, Oita 879-5593, Japan

\begin{abstract}
Yoshio Yamaoka ${ }^{\dagger}$
Department of Environmental and Preventive Medicine, Oita University Faculty of Medicine, 1-1 Baylor College of Medicine and Michael E. DeBakey Veterans Affairs Medical Center, Houston, Texas 77030, USA
\end{abstract} \\ Idaigaoka, Hasama-machi, Yufu-City, Oita 879-5593, Japan and Department of Gastroenterology,
}

\section{Abstract}

The prevalence of Helicobacter pylori infection is decreasing gradually in Japan mainly owing to an improvement in sanitary conditions. The guidelines for $\mathrm{H}$. pylori management by the Japanese Society for Helicobacter Research, initially established in 2000 and revised in 2003, were revised dramatically in January 2009. The new guidelines accepted the use of new drugs and recommended trying the second-line eradication regimen. Moreover, the revised guidelines reflected the recent knowledge in Japan that metachronous gastric cancer prevalance is decreased significantly by the eradication of H. pylori infection. The Japanese Society for Helicobacter Research proposed that the cure of $H$. pylori infection should be presupposed to prevent gastric cancer from active gastritis universally developed in the infected subjects. Overall, the most important and dramatic revision is that all infected people are recommended to receive eradication therapy irrespective of the clinical outcomes in the Japanese population.

\section{Keywords}

guideline; Helicobacter pylori; management; resistance; treatment

\footnotetext{
(C) 2010 Expert Reviews Ltd

${ }^{\dagger}$ Author for correspondence: Department of Environment and Preventive Medicine, Faculty of Medicine, Oita University 1-1 Idaigaoka, Hasama-machi, Yufu-City, Oita 879-5593, Japan, Tel.: +81975 865 740, Fax: +81975 865 749, yyamaoka@ med.oita-u.ac.jp .

Financial \& competing interests disclosure

The project described was supported by NIH grant DK 62813. The authors have no other relevant affiliations or financial involvement with any organization or entity with a financial interest in or financial conflict with the subject matter or materials discussed in the manuscript apart from those disclosed.

No writing assistance was utilized in the production of this manuscript.
} 


\section{The prevalence of $\boldsymbol{H}$. pylori infection in Japan}

The prevalence of Helicobacter pylori infection ranges widely between developed and developing countries. In developing regions, such as India, Saudi Arabia, Vietnam and Africa, the infection rate is high and approximately $80 \%$ of the population is infected by this bacterium by 20 years of age [1]. By contrast, the infection rate is as low as 10-20\% in developed countries, and increases at a rate of approximately $1 \%$ per year [2]. It is supposed that the state of environmental hygiene, such as the development of a modern water and sewage system, is related to the $H$. pylori infection rate. In Japan, the prevalence of $H$. pylori infection is also believed to be related to social environment, especially during childhood [3].

The prevalence of $H$. pylori infection in Japan is very low in children under 10 years old ( $5 \%)$ and it increases with age [4]. Interestingly, the younger generation have a similar pattern to that seen in developed countries, with low prevalence of $H$. pylori infection; whereas the older generation has the pattern seen in developing countries, with high prevalence. In 1992, Asaka et al. evaluated the prevalence of $H$. pylori infection among Japanese individuals undergoing an annual medical check-up $(n=426)$ and reported that prevelance increased with age [4] (Figure 1). The authors showed that $\mathrm{H}$. pylori infection rates gradually increased up to 39 years of age (e.g., approximately 5\% in patients $0-9$ years old, $20 \%$ in those $10-19$ years old, $25 \%$ in those $20-29$ years old and $40 \%$ in those $30-39$ years old); whereas the rate was dramatically higher (i.e., $\geq 70 \%$ ) at 40 years of age and over. Overall, they concluded that the infection rate was higher among individuals born before 1950 and lower in those born thereafter. There was a rapid change in sanitary conditions and standard of living in Japan after World War II, and clean public water systems were introduced in Japan in the 1950s. This provided us with some evidence that $H$. pylori infection may be influenced by sanitary conditions. In our preliminary experiment, we also examined the prevalence of $H$. pylori infection using the urine antibody test (Otsuka Pharmaceutical Co., Tokyo, Japan) [5] for 4331 first-visited patients in Oita University hospital, Japan, between 2002 and 2006 (Figure 1). As expected, the prevalence of H. pylori infection increased with age. In our study, 10 years had passed since the report by Asaka et al.; therefore, as expected, when their results were simply shifted by 10 years, our results were in close agreement with theirs for those under 40 years old. However, they reported that the prevalence in patients aged over 40 years of age was over $70 \%$; whereas we found a prevalence of $60 \%$ in patients aged over 50 years. There are several possibilities that may explain the discrepancies. For example, the $H$. pylori detection methods were different (i.e., they used serum antibody ELISA). Moreover, they chose a cutoff optimal density by themselves, which might have caused the high positive rate. Interestingly, Kumagai et al. reported that the $H$. pylori infection rate in those aged 9-70 years old decreased by $20 \%$ from 1986 to 1994 [6]. As the same population was examined longitudinally, a decrease in the prevalence was observed in every age group. The fall in the prevalence that occurred during the observation period reflected not only the changes in the rate of acquisition of $H$. pylori in childhood but also the higher rate of loss of the infection. This disappearance of $H$. pylori was thought to possibly be due to the use of anti microbials for other common infections. Thus, the H. pylori infection rate in Japan will probably continue to fall owing to the improvement of sanitary conditions and the use of antibiotics in the future.

\section{The background for the guidelines in 2009}

In Japan, the first guidelines for management of $H$. pylori infection were constructed in 2000 [7,8] (Table 1). These aimed to prepare clinicians for the task ahead in view of $H$. pylori eradication therapy becoming available. Gastric and/or duodenal ulcer were the only diseases for which $\mathrm{H}$. pylori eradication therapy was recommended. Gastric mucosa-associated lymphoid tissue (MALT) lymphoma was recommended to receive eradication therapy only at specialist institutions where satisfactory histopathologic diagnosis, endoscopic diagnosis 
(including endoscopic ultrasound) and genetic analysis can be performed, and where close follow-up is available.

The second guidelines in 2003 advanced the field greatly [9,10]. As the indication for cure of H. pylori infection, MALT lymphoma was recommended to receive eradication therapy in addition to active gastric and/or duodenal ulcer. In addition, the following three clinical outcomes were upgraded to advisable indications; early gastric cancer after endoscopic mucosal resection (EMR); atrophic gastritis; and gastric hyperplastic polyp. Thus, the 2003 guidelines included evidence-based recommendations for indication, diagnosis and therapy.

The guidelines were revised dramatically again in January 2009, 6 years after the second revision [11]. This revision was based on the approval of the Japanese national health insurance system for second-line eradication, the evidence for the relationship between $H$. pylori and gastric cancer and also the relationship with various extragastric diseases. The results from a large-scale multicenter study in Japan published in 2008 helped the revision grately [12]. In the study, patients with early gastric cancer who received EMR were divided randomly into the eradication treatment group and the noneradication control group, and the development of metachronous recurrence was followed-up for 3 years. As a result, metachronous recurrence was significantly inhibited in the eradication group. That study clearly showed that the cure of H. pylori infection led to a decrease in the development of gastric cancer. This shows that even after the removal of gastric cancer by EMR, the subsequent development of gastric cancer was significantly inhibited by the cure of $\mathrm{H}$. pylori infection, confirming the importance of careful management of $H$. pylori-related gastritis.

\section{Guidelines 2009 Indications for H. pylori eradication therapy}

The most important point in the new guidelines was that all ' $H$. pylori infection' subjects were put into the 'level A' group for eradication therapy (strongly recommended based on strong evidence). This is based on the following evidence.

Helicobacter pylori infection is reported to cause various upper GI tract diseases, such as atrophic gastritis, gastric/duodenal ulcer, gastric cancer, gastric MALT lymphoma and gastric hyperplastic polyp [13-16]. Although not all infected people have the aforementioned diseases, an infected person is at a high risk of developing these diseases. Therefore, it is expected that successful eradication therapy will be connected with the improvement of histological gastritis and with the prevention of subsequent diseases. This may contribute to the prevention of gastric cancer development, which is one of the biggest health problems in Japan. For such reasons, the Japanese Society for Helicobacter Research (JSHR) concluded that all $H$. pylori infections should be considered as an indication for eradication irrespective of the background diseases.

Since all $H$. pylori infections were put into level A for recommendation of eradication, the new guidelines showed the level of evidence for each disease based on the evidence about the effect of the eradication (Table 2). The level of evidence for each recommendation is classified from level I to level VI (Table 3); however, an insurance system (approval of the Japanese national health insurance system) was not taken into consideration.

\section{Gastric/duodenal ulcer (evidence level I)}

There are many reports from all over the world showing that recurrence of the $\mathrm{H}$. pylori-positive gastric/duodenal ulcers were inhibited by successful eradication therapy, and that complications such as bleeding were also decreased $[17,18]$. Therefore, $H$. pylori eradication therapy was initially selected as the first choice for gastric/duodenal ulcer treatment in the Japanese guideline in 2003 [9]. 
Although successful eradication therapy can reduce the development of peptic ulcers and the risk of bleeding accompanying NSAIDs and low-dose aspirin use, the effects were still limited [19-21]. For example, these high-risk patients need gastric acid control, such as proton-pump inhibitors (PPIs), even after successful eradication therapy [22].

\section{Gastric MALT lymphoma (evidence level III)}

The cure of $H$. pylori infection has been reported to improve the histological and endoscopic findings for approximately $60-80 \%$ of $H$. pylori-infected patients with gastric MALT lymph oma in European countries [23-25]. Thus, the cure of $H$. pylori infection was selected as a first choice in these countries. In Japan, a largescale multicenter clinical study for gastric MALT lymph oma was also completed [26]. The independent factors that can predict the effect of eradication therapy were the presence of $H$. pylori infection, clinical stage, depth of invasion and the API2-MALT1 chimeric transcript. However, conducting a placebo controlled randomized trial is difficult owing to the low frequency and the nature of this disease. Therefore, the evidence level was low, which was different from the recommendation level introduced by the Maastricht III guidelines, where the level of evidence was high (i.e., level Ic). Prognostic evaluation will be required over a long period of time in the future.

\section{Idiopathic thrombocytopenic purpura (evidence level I)}

Approximately 30,000 patients are known to have chronic idiopathic thrombocytopenic purpura (ITP) in Japan. Since Gasbarrini et al. initially reported the usefulness of the cure of H. pylori infection for chronic ITP patients in an Italian population [27], there have been many subsequent reports supporting the original findings. A meta-analysis of 17 papers showed that the platelet count increased significantly after the cure of $H$. pylori infection [28]. In Japan, it is also reported that the cure of $H$. pylori infection resulted in the increase in the platelet count by $40-60 \%$ compared with that in pretreatment or that of $H$. pylori-positive chronic ITP patients [29-31]. On the other hand, the effects of successful eradication therapy were unclear in the USA, Spain and France [32-36]. Although the reasons are not clear, it is reported that both bacterial and host factors are involved in the discrepancy [32-36]. However, successful eradication therapy is effective, at least in Japan; thus, the level of evidence in the new guidelines is I.

\section{Following EMR for early gastric cancer (evidence level II)}

In 1997 it was reported in Japan that the cure of $H$. pylori infection suppressed the development of metachronous gastric cancer after EMR for early gastric cancer [37]. Since this report was not a randomized controlled trial (RCT), a large-scale multicenter RCT was planned and successfully performed recently in Japan. Importantly, successful eradication therapy suppressed the incidence of meta chronous gastric cancer [12]. Therefore, H. pylori eradication therapy is strongly recommended after EMR treatment for early gastric cancer.

\section{Atrophic gastritis (evidence level I)}

Atrophic gastritis was a 'Class B' (advisable) disease for H. pylori eradication in the 2003 guidelines. A meta-analysis showed that successful eradication therapy improved atrophic gastritis [38]. Moreover, successful eradication therapy against atrophic gastritis followed the suppression of the incidence of metachronous gastric cancer [12]. Thus, the level of evidence in the new guidelines is I.

\section{Gastric hyperplastic polyp (evidence level II)}

Randomized controlled trials showed that the effectiveness of the successful eradication therapy for gastric hyperplastic polyp was approximately $70 \%$ [39,40]. Thus, the level of evidence in the new guidelines is II. 


\section{Functional dyspepsia (evidence level I)}

Since the eradication therapy was recommended by the Maastricht III Consensus report regarding functional dyspepsia [41], the level of evidence became I in the new guidelines. However, the effects are variable in reports from Japan [42-45]. We also examined the $H$. pylori-positive rate of patients who presented with dyspepsia. The $H$. pylori-positive rate in dyspeptic patients was approximately $20 \%$ in patients between 20 and 39 years of age, meaning that the remaining $80 \%$ were $H$. pylori-negative [46]. This suggested that factors other than H. pylori are related to the dyspeptic symptom in young people. Further studies may be necessary to evaluate the evidence levels for functional dyspepsia in Japan.

\section{Reflux esophagitis (evidence level II)}

An increase in the incidence and symptoms of reflux esophagitis rarely occurs after $H$. pylori eradication therapy $[47,48]$. Therefore, the guidelines suppose that the presence of reflux esophagitis will not be an impediment to performing H. pylori eradication therapy. However, these reports also showed that the risk of the incidence of reflux esophagitis was high in patients with hiatus hernia after $H$. pylori eradication therapy [48,49], thus it is necessary to explain this point to patients before eradication therapy. Therefore, the level of evidence in the new guidelines is II.

\section{Iron deficiency anemia \& chronic urticaria (evidence level III)}

There is not enough evidence showing the effectiveness of eradication for these diseases, thus the level of evidence in the new guidelines is III.

\section{Diagnosis of $\mathrm{H}$. pylori infection \& assessment of $\mathrm{H}$. pylori eradication}

There are currently six diagnostic methods recommended to detect $H$. pylori infection in the new guidelines. These include: culture, histology, rapid urease test, measurement of $H$. pylori antibody, urea breath tests and measurement of $H$. pylori antigen in feces based on enzyme immunoassay or immunochromatography. Fasting periods using PPIs before the test for preventing the false-negative results were shortened from 4 to 2 weeks [50-52]. Assessment of the successful eradication should be performed at least 4 weeks after the completion of treatment, which was unchanged from the previous guidelines in 2003.

\section{Treatment of $\mathrm{H}$. pylori infection}

The approved eradication therapy for the Japanese national health insurance system is shown in Box 1. Lansoprazol, amoxicillin (AMPC) and clarithromycin (CAM); omeprazole, AMPC and CAM (800 mg); and omeprazole, AMPC and CAM (400 mg) were approved for the Japanese health insurance system in 2000, 2002 and 2007, respectively. The effectiveness of rabeprazole for primary eradication has been established [53]; therefore, rabeprazole was newly added as the first-line eradication regimen in January 2007. Moreover, the great effectiveness ( $\sim 90 \%)$ of the second-line eradication regimen (PPI, AMPC and metronidazole [MNZ]), recommended in the 2003 guidelines, was confirmed [54-57], and the therapy was also approved by the Japanese health insurance system in August 2007 (Box 1).

Clarithromycin-resistant $H$. pylori is the main cause of unsuccessful eradication therapy. In the JSHR, annual surveillance of CAM-resistant $H$. pylori was conducted for 5 years from 2002 [58]. As a result, the mean nationwide CAM resistance rates were increasing rapidly; $18.9 \%$ (2002), $21.2 \%$ (2003), 27.7\% (2004), 29.0\% (2005) and 27.2\% (2006). The increase in CAM use in the fields of pediatrics, respiratory disease and otorhinolaryngology is considered to be the cause. In our institution, the successful eradication rate with lansoprazol, AMPC and CAM 
(400 mg) tended to decrease between the years 2000-2001 and 2006-2007 (82.5 vs 75.7\%,

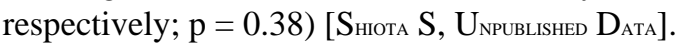

The successful eradication rate by the second-line eradication regimen is over $90 \%$. Using the MNZ breakpoint of $8 \mu \mathrm{g} / \mathrm{ml}$ established by the European Study Group, resistance rates were not changed between 2002-2003 and 2004-2005 (4.9 and 3.3\%, respectively) [58]. However, unsuccessful cases also exist and it is necessary to investigate an acceptable third-line eradication that will be useful in the Japanese population as soon as possible. The guidelines state potential third-line eradication programs, such as a PPI, AMPC and levofloxacin; or a PPI and high-dose AMPC. However, the evidence for these therapies is currently insufficient.

\section{Box 1. Eradication therapy covered by the Japanese national health insurance system}

\section{First-line therapy}

- Lansoprazole $30 \mathrm{mg}$ twice daily, omepazole $20 \mathrm{mg}$ twice daily, rabeprazole $10 \mathrm{mg}$ twice daily

- Amoxicillin $750 \mathrm{mg}$ twice daily

- Clarithromycin 200 or $400 \mathrm{mg}$ twice daily (for 1 week)

\section{Second-line therapy}

- All proton-pump inhibitors covered as first-line therapy

- Amoxicillin $750 \mathrm{mg}$ twice daily

- Metronidazole $500 \mathrm{mg}$ twice daily (for 1 week)

\section{Expert commentary}

We have described the concept of $H$. pylori infection as used in the Japanese guidelines in 2009 , and shown a positive indication for eradication. Based on the evidence in Japan, the JSHR strongly recommend performing $H$. pylori eradication therapy for patients following endoscopic mucosal resection for early gastric cancer. This should be unique to Japan since most gastric cancer has been found at an early stage, whereas the prevalence of finding the disease at an early stage is usually rare in other countries. A successful eradication therapy leads to the improvement of histological gastritis, and the clinical outcomes that might be developed by $H$. pylori infection, such as peptic ulcer and gastric cancer, may be prevented. However, it is important to recognize that gastric cancer would develop after successful eradication therapy, especially with the case of strong atrophy in gastric corpus. This is currently a hot topic at the JSHR and we are now intensively researching the special characteristics of gastric cancer developed after the cure of $H$. pylori infection.

Another important concern is that the increase of CAM resistance has caused a decline in the successful eradication rate. A success of eradication therapy is been brought about by using MNZ in the place of CAM for patients failing primary eradication therapy. It is thought that successful second-line eradication therapy causes a lower $H$. pylori infection rate. However, MNZ-resistant anaerobic bacteria in addition to H. pylori may also increase, and surveillance is important.

The major problem in Japan is that the diseases recommended by the guidelines are still not approved by the Japanese national health insurance system. Currently, peptic ulcer is the only 'approved' indication for $H$. pylori eradication therapy. Thus, most $H$. pylori infected-people, except those with gastric/duodenal ulcers, cannot receive the benefit of the eradication 
treatment. Recently, some $H$. pylori-positive patients without gastric/duodenal ulcer have been able to receive the $H$. pylori eradication therapy in Japan, because some institutions have built special clinics for the diagnosis of and therapy for $H$. pylori where patients can be treated without the Japanese national health insurance system. It is expected that the diseases recommended by the guidelines will be approved by the Japanese national health insurance system in the future. If all the infected people are cured, the development of many peptic ulcers and gastric cancers will be controlled in Japan in the future.

\section{Five-year view}

The knowledge we consider to be required for the management of $H$. pylori infection in Japan over the next 5 years is as follows:

- The elucidation of a relationship between NSAIDs, low-dose aspirin and H. pylori infection;

- Identification of factor(s) that can predict the effectiveness of the eradication therapy for gastric MALT lymphoma, ITP and following EMR for early gastric cancer and atrophic gastritis, with long-term observation;

- RCTs with placebo for functional dyspepsia in Japan. Construction of further evidence regarding iron deficiency anemia and chronic urticaria;

- Investigation of the resistance rate to clarithromycin or metronidazole. Evidence of the effectiveness of the third-line eradication therapy;

- Development of a diagnostic method for other Helicobacter species, such as Helicobacter hailmannii related to gastric MALT lymphoma and Helicobacter hepaticus and Helicobacter bilis related to the hepatobiliary disease;

- Extending the approval of the Japanese national health insurance system of diseases that the guidelines recommend.

\section{Key issues}

- The Helicobacter pylori infection rate in Japan is falling gradually.

- We have described the concept of $H$. pylori infection, as used in the Japanese guidelines in 2009, and shown a positive indication for eradication. Based on the evidence from Japan, the Japanese Society for Helicobacter Research strongly recommends performing $H$. pylori eradication therapy for patients after endoscopic mucosal resection for early gastric cancer.

- It is important to recognize that gastric cancer would be developed even after the cure of $\mathrm{H}$. pylori infection in the case of strong atrophy in gastric corpus.

- It is necessary to identify the factors that can predict the effectiveness of the eradication for gastric mucosa-associated lymphoid tissue lymphoma, idiopathic thrombocytopenic purpura and after early gastric cancer, atrophic gastritis and long-term observation is needed.

- Further evidence of functional dyspepsia, iron deficiency anemia and chronic urticaria is necessary.

- The increase of clarithromycin-resistant $H$. pylori has caused a decline in the successful rate of first-line eradication. The success of eradication therapy is acheived by using metronidazole in place of clarithromycin for patients failing first-line eradication therapy. 
- The major problem in Japan is that the diseases recommended by the guidelines are not approved by the Japanese national health insurance system.

\section{References}

Papers of special note have been highlighted as:

* of interest

** of considerable interest

1. Graham D, Adam E, Reddy G, et al. Seroepidemiology of Helicobacter pylori infection in India. Comparison of developing and developed countries. Dig. Dis. Sci 1991;36(8):1084-1088. [PubMed: 1864201]

2. Graham D, Malaty H, Evans D, Evans DJ, Klein P, Adam E. Epidemiology of Helicobacter pylori in an asymptomatic population in the United States. Effect of age, race, and socioeconomic status. Gastroenterology 1991;100(6):1495-1501. [PubMed: 2019355]

3. Karita M, Teramukai S, Matsumoto S. Risk of Helicobacter pylori transmission from drinking well water is higher than that from infected intrafamilial members in Japan. Dig. Dis. Sci 2003;48(6):10621067. [PubMed: 12822863]

4. Asaka M, Kimura T, Kudo M, et al. Relationship of Helicobacter pylori to serum pepsinogens in an asymptomatic Japanese population. Gastroenterology 1992;102(3):760-766. [PubMed: 1537513] * First report showing the prevalence of Helicobacter pylori in Japan.

5. Graham D, Reddy S. Rapid detection of anti-Helicobacter pylori IgG in urine using immunochromatography. Aliment. Pharmacol. Ther 2001;15(5):699-702. [PubMed: 11328264]

6. Kumagai T, Malaty H, Graham D, et al. Acquisition versus loss of Helicobacter pylori infection in Japan: results from an 8-year birth cohort study. J. Infect. Dis 1998;178(3):717-721. [PubMed: 9728540]

7. Japanese Society for Helicobacter Research Committee on Guidelines. Guidelines for the management of Helicobacter pylori infection in Japan. J. Jpn Soc. Helicobacter Res 2000;1(Suppl. 1):1-12. ** First guideline for the management of $H$. pylori in Japan.

8. Asaka M, Satoh K, Sugano K, et al. Guidelines in the management of Helicobacter pylori infection in Japan. Helicobacter 2001;6(3):177-186. [PubMed: 11683920] * Description of the first guideline.

9. Japanese Society for Helicobacter Research Committee on Guidelines. Guidelines for the management of Helicobacter pylori infection in Japan. Revised edition. J. Jpn Soc. Helicobacter Res 2003;4(Suppl. 1):1-15. ** Second guideline for the management of $H$. pylori in Japan.

10. Fujioka T, Yoshiiwa A, Okimoto T, Kodama M, Murakami K. Guidelines for the management of Helicobacter pylori infection in Japan: current status and future prospects. J. Gastroenterol 2003;42 (Suppl. 17):3-6. [PubMed: 17238017] * Description of the second guideline.

11. Japanese Society for Helicobacter Research Committee on Guidelines. Guidelines for the management of Helicobacter pylori infection in Japan. Revised edition. J. Jpn Soc. Helicobacter Res 2009;10(Suppl. 1):1-25.

12. Fukase K, Kato M, Kikuchi S, et al. Effect of eradication of Helicobacter pylori on incidence of metachronous gastric carcinoma after endoscopic resection of early gastric cancer: an open-label, randomised controlled trial. Lancet 2008;372(9636):392-397. [PubMed: 18675689] * Randomized controlled trial in Japan showing that the incidence of metachronous gastric cancer is significantly inhibited by the eradication of $H$. pylori infection.

13. NIH Consensus Conference. Helicobacter pylori in peptic ulcer disease. NIH Consensus Development Panel on Helicobacter pylori in Peptic Ulcer Disease. JAMA 1994;272(1):65-69. [PubMed: 8007082]

14. Uemura N, Okamoto S, Yamamoto S, et al. Helicobacter pylori infection and the development of gastric cancer. N. Engl. J. Med 2001;345(11):784-789. [PubMed: 11556297]

15. Wotherspoon A, Ortiz-Hidalgo C, Falzon M, Isaacson P. Helicobacter pylori-associated gastritis and primary B-cell gastric lymphoma. Lancet 1991;338(8776):1175-1176. [PubMed: 1682595] 
16. D'Elios M, Appelmelk B, Amedei A, Bergman M, Del Prete G. Gastric autoimmunity: the role of Helicobacter pylori and molecular mimicry. Trends Mol. Med 2004;10(7):316-323. [PubMed: 15242679]

17. Gisbert J, Khorrami S, Carballo F, Calvet X, Gené E, Dominguez-Muñoz J. H. pylori eradication therapy vs antisecretory noneradication therapy (with or without long-term maintenance antisecretory therapy) for the prevention of recurrent bleeding from peptic ulcer. Cochrane Database Syst. Rev 2004:CD004062. [PubMed: 15106235]

18. Miwa H, Sakaki N, Sugano K, et al. Recurrent peptic ulcers in patients following successful Helicobacter pylori eradication: a multicenter study of 4940 patients. Helicobacter 2004;9(1):9-16. [PubMed: 15156899]

19. Lai K, Lau C, Ip W, et al. Effect of treatment of Helicobacter pylori on the prevention of gastroduodenal ulcers in patients receiving long-term NSAIDs: a double-blind, placebocontrolled trial. Aliment. Pharmacol. Ther 2003;17(6):799-805. [PubMed: 12641502]

20. Vergara M, Catalán M, Gisbert J, Calvet X. Meta-analysis: role of Helicobacter pylori eradication in the prevention of peptic ulcer in NSAID users. Aliment. Pharmacol. Ther 2005;21(12):1411-1418. [PubMed: 15948807]

21. Lai K, Lam S, Chu K, et al. Lansoprazole for the prevention of recurrences of ulcer complications from long-term low-dose aspirin use. N. Engl. J. Med 2002;346(26):2033-2038. [PubMed: 12087138]

22. Lai K, Lam S, Chu K, et al. Lansoprazole reduces ulcer relapse after eradication of Helicobacter pylori in nonsteroidal anti-inflammatory drug users - a randomized trial. Aliment. Pharmacol. Ther 2003;18(8):829-836. [PubMed: 14535877]

23. Stolte M, Eidt S. Healing gastric MALT lymphomas by eradicating H. pylori? Lancet 1993;342(8871): 568. [PubMed: 8102714]

24. Wotherspoon A, Doglioni C, Diss T, et al. Regression of primary low-grade B-cell gastric lymphoma of mucosa-associated lymphoid tissue type after eradication of Helicobacter pylori. Lancet 1993;342 (8871):575-577. [PubMed: 8102719]

25. Bayerdörffer E, Neubauer A, Rudolph B, et al. Regression of primary gastric lymphoma of mucosaassociated lymphoid tissue type after cure of Helicobacter pylori infection. MALT Lymphoma Study Group. Lancet 1995;345(8965):1591-1594. [PubMed: 7783535]

26. Inagaki H, Nakamura T, Li C, et al. Gastric MALT lymphomas are divided into three groups based on responsiveness to Helicobacter pylori eradication and detection of API2-MALT1 fusion. Am. J. Surg. Pathol 2004;28(12):1560-1567. [PubMed: 15577674]

27. Gasbarrini A, Franceschi F, Tartaglione R, Landolfi R, Pola P, Gasbarrini G. Regression of autoimmune thrombocytopenia after eradication of Helicobacter pylori. Lancet 1998;352(9131):878. [PubMed: 9742983]

28. Franchini M, Cruciani M, Mengoli C, Pizzolo G, Veneri D. Effect of Helicobacter pylori eradication on platelet count in idiopathic thrombocytopenic purpura: a systematic review and meta-analysis. J. Antimicrob. Chemother 2007;60(2):237-246. [PubMed: 17561502]

29. Ando K, Shimamoto T, Tauchi T, et al. Can eradication therapy for Helicobacter pylori really improve the thrombocytopenia in idiopathic thrombocytopenic purpura? Our experience and a literature review. Int. J. Hematol 2003;77(3):239-244. [PubMed: 12731666]

30. Fujimura K, Kuwana M, Kurata Y, et al. Is eradication therapy useful as the first line of treatment in Helicobacter pylori-positive idiopathic thrombocytopenic purpura? Analysis of 207 eradicated chronic ITP cases in Japan. Int. J. Hematol 2005;81(2):162-168. [PubMed: 15765787]

31. Sato R, Murakami K, Watanabe K, et al. Effect of Helicobacter pylori eradication on platelet recovery in patients with chronic idiopathic thrombocytopenic purpura. Arch. Intern. Med 2004;164(17): 1904-1907. [PubMed: 15451766]

32. Everhart J, Kruszon-Moran D, Perez-Perez G, Tralka T, McQuillan G. Seroprevalence and ethnic differences in Helicobacter pylori infection among adults in the United States. J. Infect. Dis 2000;181 (4):1359-1363. [PubMed: 10762567]

33. Michel M, Khellaf M, Desforges L, et al. Autoimmune thrombocytopenic Purpura and Helicobacter pylori infection. Arch. Intern. Med 2002;162(9):1033-1036. [PubMed: 11996614] 
34. Takahashi T, Yujiri T, Tanizawa Y. Helicobacter pylori and chronic ITP: the discrepancy in the clinical responses to eradication therapy might be due to differences in the bacterial strains. Blood 2004;104(2):594. [PubMed: 15231581]

35. Byrne M, Kerrigan S, Corcoran P, et al. Helicobacter pylori binds von Willebrand factor and interacts with GPIb to induce platelet aggregation. Gastroenterology 2003;124(7):1846-1854. [PubMed: 12806618]

36. Veneri D, De Matteis G, Solero P, et al. Analysis of B- and T-cell clonality and HLA class II alleles in patients with idiopathic thrombocytopenic purpura: correlation with Helicobacter pylori infection and response to eradication treatment. Platelets 2005;16(5):307-311. [PubMed: 16011982]

37. Uemura N, Mukai T, Okamoto S, et al. Effect of Helicobacter pylori eradication on subsequent development of cancer after endoscopic resection of early gastric cancer. Cancer Epidemiol. Biomarkers Prev 1997;6(8):639-642. [PubMed: 9264278]

38. Rokkas T, Pistiolas D, Sechopoulos P, Robotis I, Margantinis G. The long-term impact of Helicobacter pylori eradication on gastric histology: a systematic review and meta-analysis. Helicobacter 2007;12(Suppl. 2):32-38. [PubMed: 17991174]

39. Ohkusa T, Takashimizu I, Fujiki K, et al. Disappearance of hyperplastic polyps in the stomach after eradication of Helicobacter pylori. A randomized, clinical trial. Ann. Intern. Med 1998;129(9):712715. [PubMed: 9841603]

40. Ji F, Wang Z, Ning J, Wang Q, Chen J, Li Y. Effect of drug treatment on hyperplastic gastric polyps infected with Helicobacter pylori: a randomized, controlled trial. World J. Gastroenterol 2006;12 (11):1770-1773. [PubMed: 16586550]

41. Malfertheiner P, Megraud F, O'Morain C, et al. Current concepts in the management of Helicobacter pylori infection: the Maastricht III Consensus Report. Gut 2007;56(6):772-781. [PubMed: 17170018]

42. Miwa H, Hirai S, Nagahara A, et al. Cure of Helicobacter pylori infection does not improve symptoms in non-ulcer dyspepsia patients-a double-blind placebo-controlled study. Aliment. Pharmacol. Ther 2000;14(3):317-324. [PubMed: 10735925]

43. Kamada T, Haruma K, Hata J, et al. The long-term effect of Helicobacter pylori eradication therapy on symptoms in dyspeptic patients with fundic atrophic gastritis. Aliment. Pharmacol. Ther 2003;18 (2):245-252. [PubMed: 12869086]

44. Azuma T, Ito Y, Suto H, et al. The effect of Helicobacter pylori eradication therapy on dyspepsia symptoms in industrial workers in Japan. Aliment. Pharmacol. Ther 2001;15(6):805-811. [PubMed: 11380318]

45. Suzuki H, Masaoka T, Sakai G, Ishii H, Hibi T. Improvement of gastrointestinal quality of life scores in cases of Helicobacter pylori-positive functional dyspepsia after successful eradication therapy. J. Gastroenterol. Hepatol 2005;20(11):1652-1660. [PubMed: 16246181]

46. Shiota S, Murakami K, Takayama A, et al. Evaluation of Helicobacter pylori status and endoscopic findings among new outpatients with dyspepsia in Japan. J. Gastroenterol 2009;44(9):930-934. [PubMed: 19568686]

47. Kawanishi M. Development of reflux esophagitis following Helicobacter pylori eradication. J. Gastroenterol 2005;40(11):1024-1028. [PubMed: 16322945]

48. Sasaki A, Haruma K, Manabe N, Tanaka S, Yoshihara M, Chayama K. Long-term observation of reflux oesophagitis developing after Helicobacter pylori eradication therapy. Aliment. Pharmacol. Ther 2003;17(12):1529-1534. [PubMed: 12823156]

49. Tsukada K, Miyazaki T, Katoh H, et al. The incidence of reflux oesophagitis after eradication therapy for Helicobacter pylori. Eur. J. Gastroenterol. Hepatol 2005;17(10):1025-1028. [PubMed: 16148546]

50. Chey W. Proton pump inhibitors and the urea breath test: how long is long enough? Am. J. Gastroenterol 1997;92(4):720-721. [PubMed: 9128344]

51. Laine L, Estrada R, Trujillo M, Knigge K, Fennerty M. Effect of proton-pump inhibitor therapy on diagnostic testing for Helicobacter pylori. Ann. Intern. Med 1998;129(7):547-550. [PubMed: 9758575] 
52. Graham D, Opekun A, Hammoud F, et al. Studies regarding the mechanism of false negative urea breath tests with proton pump inhibitors. Am. J. Gastroenterol 2003;98(5):1005-1009. [PubMed: 12809820]

53. Kuwayama H, Asaka M, Sugiyama T, et al. Rabeprazole-based eradication therapy for Helicobacter pylori: a large-scale study in Japan. Aliment. Pharmacol. Ther 2007;25(9):1105-1113. [PubMed: 17439512]

54. Murakami K, Sato R, Okimoto T, et al. Efficacy of triple therapy comprising rabeprazole, amoxicillin and metronidazole for second-line Helicobacter pylori eradication in Japan, and the influence of metronidazole resistance. Aliment. Pharmacol. Ther 2003;17(1):119-123. [PubMed: 12492740]

55. Shimoyama T, Fukuda S, Mikami T, Fukushi M, Munakata A. Efficacy of metronidazole for the treatment of clarithromycin-resistant Helicobacter pylori infection in a Japanese population. J. Gastroenterol 2004;39(10):927-930. [PubMed: 15549444]

56. Fukuda S, Shimoyama T, Tanaka M, Nakasato F, Fukushi M, Munakata A. Duration of the metronidazole-containing regimen for eradication of Helicobacter pylori infection in northern Japan. Jpn J. Infect. Dis 2006;59(6):367-369. [PubMed: 17186954]

57. Murakami K, Okimoto T, Kodama M, Sato R, Watanabe K, Fujioka T. Evaluation of three different proton pump inhibitors with amoxicillin and metronidazole in retreatment for Helicobacter pylori infection. J. Clin. Gastroenterol 2008;42(2):139-142. [PubMed: 18209581]

58. Kobayashi I, Murakami K, Kato M, et al. Changing antimicrobial susceptibility epidemiology of Helicobacter pylori strains in Japan between 2002 and 2005. J. Clin. Microbiol 2007;45(12):40064010. [PubMed: 17942652] 


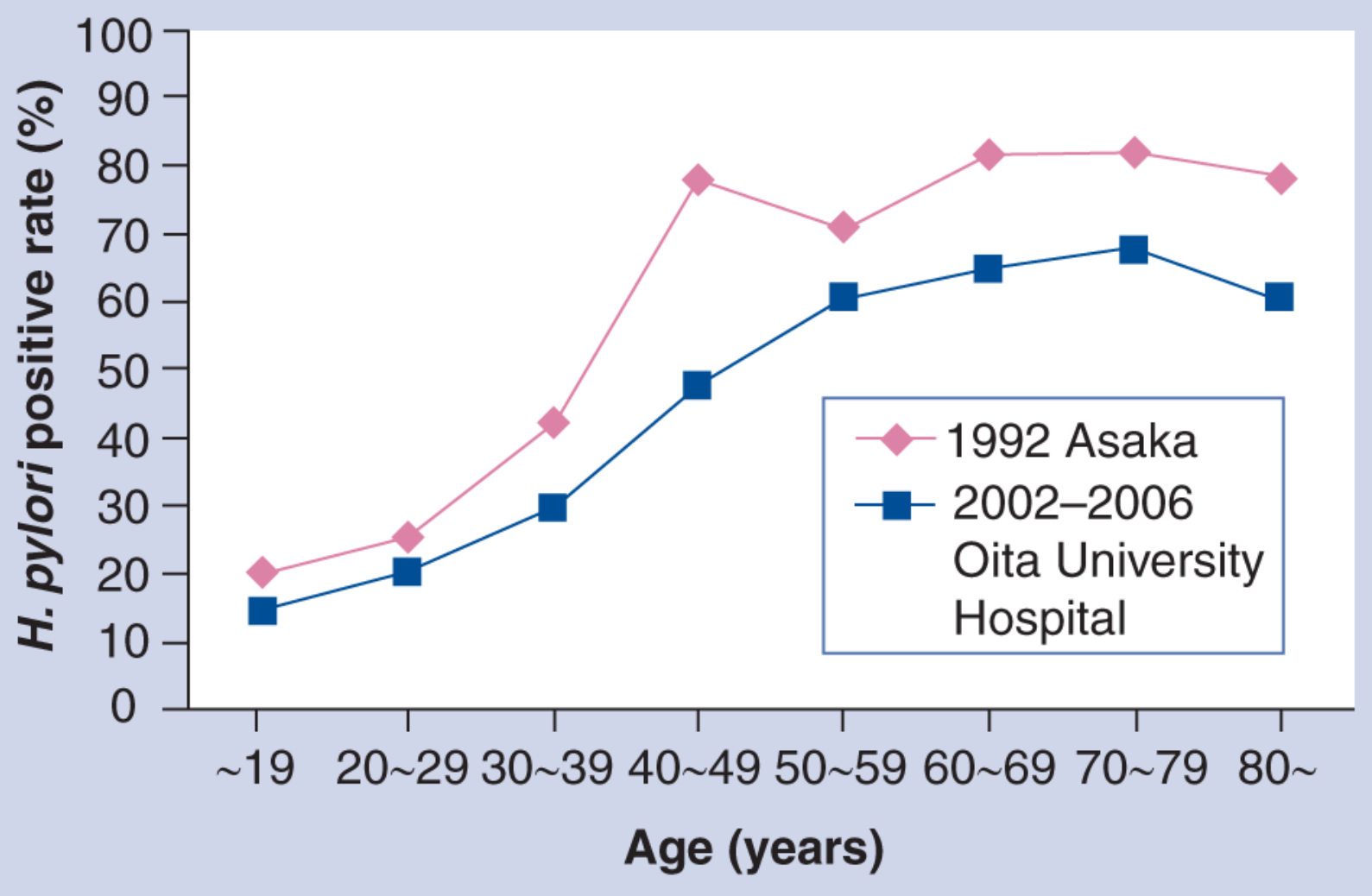

Figure 1.

Prevalence of $H$. pylori in Japan. 

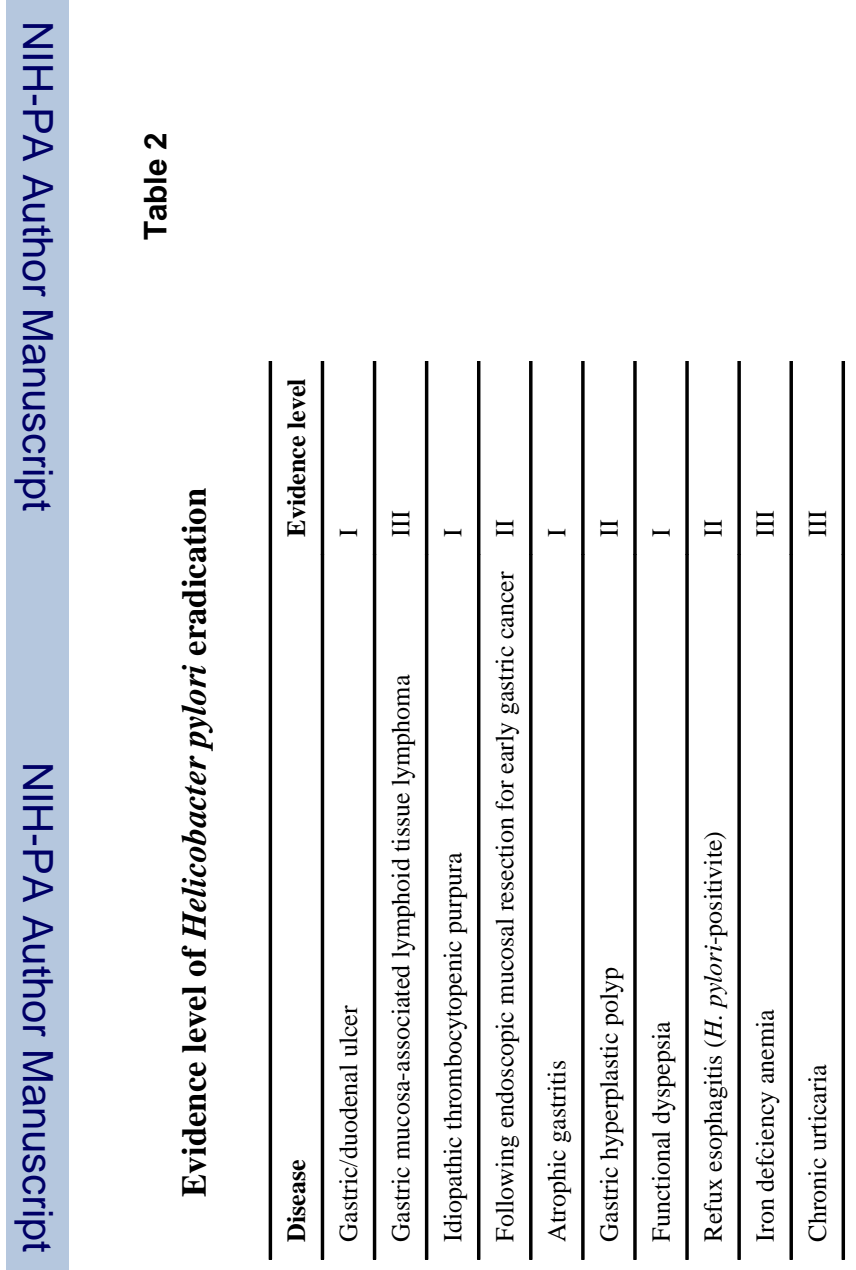

Expert Rev Gastroenterol Hepatol. Author manuscript; available in PMC 2011 February 1. 
